\title{
Incremento da sobrevivência de colmos em cevada através da adubação nitrogenada no período de alongamento dos colmos
}

\author{
Shoots survival increment in barley by nitrogen supply in the shoots elongation stage
}

\author{
Anderson Fernando Wamser ${ }^{\mathrm{I}}$ Claudio Mario Mundstock ${ }^{\mathrm{II}}$
}

\section{RESUMO}

\begin{abstract}
O trabalho teve como objetivos avaliar o acúmulo de matéria seca (MS) e de nitrogênio $(N)$ da parte aérea de plantas de cevada e a taxa de sobrevivência de colmos em função da época de aplicação de N. Um experimento foi realizado em Eldorado do Sul, $R S$, em 2000, testando seis épocas de aplicação de $N$ (emergência das plântulas, emissão da $3^{\underline{a}}$ folha, $5^{\underline{a}}$ folha, $7 \underline{a}$ folha, 9므 folha do colmo principal (CP) e no emborrachamento) e duas doses de $N$ (40 e $\left.80 \mathrm{~kg} \mathrm{ha}^{-1}\right)$. Foram determinados os acúmulos de MS e $N$ da parte aérea no período entre o início do alongamento dos colmos e o florescimento e a taxa de sobrevivência de colmos. As aplicações de $N$ entre a emergência das plântulas e a emissão da $9^{a}$ folha do CP resultaram nas maiores taxas de acúmulo de MS. Entretanto, as maiores taxas de acúmulo de $N$ foram observadas com a aplicação de $N$ no período de alongamento dos colmos. As maiores porcentagens de sobrevivência de colmos também foram observadas com a aplicação de $N$ nesse período, mostrando a relação existente entre a necessidade de $N$ para dar aporte ao alongamento dos colmos e a mortalidade de afilhos.
\end{abstract}

Palavras-chave: Hordeum vulgare L., manejo do nitrogênio, estádio de desenvolvimento.

\section{ABSTRACT}

This study was aimed at evaluating the dry matter (DM) and nitrogen ( $N$ ) accumulation in aerial part of barley plants and the shoot survival rate in function of time of $N$ supply. An experiment was carried out in Eldorado do Sul, RS, in 2000, where six times of $N$ supply (seedling emergence; $3^{\text {rd }}$ leaf; $5^{\text {th }}$ leaf; $7^{\text {th }}$ leaf; $9^{\text {th }}$ leaf emergence and boot stage) and two $N$ rates (40 and $80 \mathrm{~kg} \mathrm{ha}^{-1}$ ) were tested. The DM and $N$ accumulation among the shoot elongation begin and the bloom stage and the shoot survival rate were determined. The $N$ supply among seedling emergence and $9^{\text {th }}$ leaf emergence stage resulted the largest DM rates accumulations. However, the largest $N$ rates accumulations were observed in shoot elongation period. The largest shoot survival rates were also observed in this period, showing the relation among the $N$ necessity to support the shoot elongation process and the shoot mortality.

Key words: Hordeum vulgare L., nitrogen management, growth stages.

\section{INTRODUÇÃO}

O desenvolvimento de um sistema de manejo do nitrogênio (N) para a cultura da cevada (Hordeum vulgare L.) conduz à necessidade de se estudar o acúmulo de matéria seca (MS) e de nitrogênio (N) pelas plantas em resposta à adubação nitrogenada. Segundo RAO \& DAO (1996), informações sobre o acúmulo de $\mathrm{N}$ ao longo dos estádios de desenvolvimento são importantes para predizer as necessidades do nutriente e para maximizar o rendimento de grãos e a eficiência no uso do N. Para os cereais de estação fria, as evoluções de MS e N da parte aérea seguem um padrão sigmoidal, como descrito por LAL et al. (1978) e DARROCH \& FOWLER (1990).

\footnotetext{
IEstação Experimental de Caçador, Empresa de Pesquisa Agropecuária e Extensão Rural de Santa Catarina (EPAGRI). Rua Abílio Franco, 1500, Bairro Bom Sucesso, CP 591, 89500-000, Caçador, SC, Brasil. E-mail: afwamser@epagri.sc.gov.br. Autor para correspondência.

IIDepartamento de Plantas de Lavoura, Faculdade de Agronomia, Universidade Federal do Rio Grande do Sul (UFRGS). Porto Alegre, RS, Brasil.
} 
Seguindo esse padrão, o acúmulo de MS e N a partir da emergência até o final do afilhamento ou o início do alongamento dos colmos é pequeno. Após esse estádio, há um rápido acúmulo de MS e $\mathrm{N}$ que se estende até a antese, seguido por uma estagnação ou redução até a maturação de colheita de grãos. Assim, o estágio compreendido entre o início do alongamento dos colmos e o florescimento é o período de maior consumo de $\mathrm{N}$, necessário para dar aporte ao rápido incremento de MS pelas plantas.

O estágio de alongamento dos colmos corresponde também ao período em que é definido o número de colmos férteis. Neste período, uma parte dos afilhos que são formados durante o crescimento dos cereais de estação fria chega à maturidade e produz grãos. Os demais senescem num fenômeno denominado de mortalidade de afilhos (SIMMONS et al., 1982). A mortalidade de afilhos pode ocorrer em qualquer classe de afilhos (DAVIDSON \& CHEVALIER, 1990), porém a época de emergência dos afilhos influencia a senescência dos mesmos (BREMNER, 1969). A maior parte dos afilhos férteis é de afilhos primários, conforme sua cronologia de aparecimento, e poucos afilhos secundários sobrevivem (DAVIDSON \& CHEVALIER, 1990). Durante o alongamento dos colmos, diversos fatores podem estar ligados à mortalidade dos afilhos defasados, como o seu menor desenvolvimento radicular (MASLE-MEYNARD, 1981) e o seu sombreamento pelos afilhos maiores (CHATURVEDI et al., 1981), os quais diminuem a sua capacidade em competir por luz e nutrientes. Da mesma forma, a demanda por $\mathrm{N}$ no estágio de alongamento dos colmos aumenta a competição entre os colmos pelo nutriente e, assim, a disponibilidade de nitrogênio neste estágio pode aumentar a sobrevivência e a participação dos afilhos já emitidos na formação do rendimento de grãos (EASSON, 1984).

O presente estudo tem por objetivos determinar o padrão de acúmulo de MS e N em cevada em resposta à aplicação de $\mathrm{N}$ em diferentes estádios de desenvolvimento da cultura e à sua relação com a sobrevivência de colmos.

\section{MATERIAL E MÉTODOS}

Foi realizado um experimento no ano de 2000, na Estação Experimental Agronômica da Universidade Federal do Rio Grande do Sul, município de Eldorado do Sul, RS, em um Argissolo Vermelho distrófico típico com os seguintes atributos químicos:
$\mathrm{pH}$ (água) $=5,3 ; \mathrm{P}$ (Mehlich-1)=6,6 $\mathrm{mg} \mathrm{dm}^{-3}$; K (Mehlich$1)=238 \mathrm{mg} \mathrm{dm}^{-3}$; matéria orgânica $(\mathrm{MO})=2,1 \%$; $\mathrm{Al}^{3+}=0,1 \mathrm{cmol}_{c} \quad \mathrm{dm}^{-3} ; \quad \mathrm{Ca}^{2+}=3,9 \mathrm{cmol}_{\mathrm{c}} \mathrm{dm}^{-3} \mathrm{e}$ $\mathrm{Mg}^{2+}=1,5 \mathrm{cmol}_{\mathrm{c}} \mathrm{dm}^{-3}, \mathrm{~V}=56 \%$.

Os tratamentos testados consistiram em seis épocas de aplicação de $\mathrm{N}$, de acordo com a escala de desenvolvimento do colmo principal (CP) proposta por HAUN (1973): 0.1 (emergência das plântulas); 2.1 (emissão da $3^{\text {a }}$ folha); 4.1 (emissão da 5a folha); 6.1 (emissão da 7ạ folha); 8.1 (emissão da 9a folha) e emborrachamento; duas doses de N (40 e 80 $\mathrm{kg} \mathrm{ha}^{-1}$ ) na forma de uréia ( $45 \%$ de $\mathrm{N}$ ) e mais um tratamento controle, sem aplicação de $\mathrm{N}$. A menor dose de $\mathrm{N}$ foi aplicada de forma única nos seis estádios de desenvolvimento, enquanto que a maior dose de $\mathrm{N}$ foi aplicada de forma única nos seis estádios de desenvolvimento ou parcelada, sendo $40 \mathrm{~kg} \mathrm{ha}^{-1}$ na emergência das plântulas e $40 \mathrm{~kg} \mathrm{ha}^{-1}$ nos demais estádios.

A semeadura direta da cultivar de cevada "MN 698" foi realizada sobre a resteva do milho no dia 23/06/2000, utilizando-se uma semeadora em linha, na densidade de 250 sementes aptas $\mathrm{m}^{-2}$. A adubação de base foi feita com a aplicação em linha de $90 \mathrm{~kg} \mathrm{ha}^{-1}$ de $\mathrm{P}_{2} \mathrm{O}_{5}$ e $45 \mathrm{~kg} \mathrm{ha}^{-1}$ de $\mathrm{K}_{2} \mathrm{O}$, nas formas de superfosfato triplo e cloreto de potássio, respectivamente. As demais práticas de manejo foram realizadas de acordo com as Recomendações técnicas da Comissão de Pesquisa de Cevada para o cultivo de cevada cervejeira em 1999 e 2000 (COMISSÃO DE PESQUISA DE CEVADA, 1999).

O delineamento experimental foi o de blocos casualizados, com quatro repetições. Cada parcela foi constituída de 11 linhas com $5 \mathrm{~m}$ de comprimento, com $17 \mathrm{~cm}$ entre linhas. O número final de colmos área ${ }^{-1}$, contabilizando somente o CP e os afilhos primários, e o número de espigas área-1 foram determinados no estádio de emissão da 9a folha do CP e de maturação de colheita, respectivamente. A sobrevivência de colmos foi obtida através da relação entre o número de espigas e de colmos área ${ }^{-1}$. $\mathrm{O}$ acúmulo de MS e $\mathrm{N}$ da parte aérea foi determinado através de sete amostragens de plantas em uma área de $0,24 \mathrm{~m}^{2}$ realizadas entre a emissão da 7 a folha do CP e o florescimento. As plantas amostradas foram secadas em estufa de aeração forçada a aproximadamente $65^{\circ} \mathrm{C}$, até peso constante, para obtenção da MS. A determinação do teor de $\mathrm{N}$ foi realizada através do método de Kjedahl, conforme TEDESCO et al. (1995).

Os dados de sobrevivência de colmos foram avaliados estatisticamente através da análise de 
variância pelo teste de F. Quando alcançada significância estatística $(\mathrm{P} \leq 0,05)$, a média dos tratamentos foi comparada pelo teste de Duncan, ao nível de significância de $5 \%$. Os dados de evolução de MS e $\mathrm{N}$ da parte aérea foram submetidos às análises de regressão e de variância pelo teste de F. Os coeficientes de regressão linear das equações ajustadas foram comparados entre si pelo teste de $\mathrm{t}$ em nível de significância de $1 \%$.

\section{RESULTADOS E DISCUSSÃO}

Todas as equações lineares ajustadas foram significativas pelo teste de $\mathrm{F}(\mathrm{P} \leq 0,05)$. Através dos coeficientes de regressão linear $(b)$ das retas, foram obtidas as taxas de acúmulo de MS e $\mathrm{N}$ da parte aérea $\left(\mathrm{kg} \mathrm{ha}^{-1} \mathrm{dia}^{-1}\right)$ em função das doses e épocas de aplicação de $\mathrm{N}$.

O tratamento-controle, sem aplicação de $\mathrm{N}$, resultou na menor taxa de acúmulo de MS da parte aérea entre os tratamentos testados (Figura 1). Comparando os coeficientes de regressão linear $(b)$ pelo teste de $t$, houve acréscimos na taxa de acúmulo de MS para todas as épocas de aplicação de $\mathrm{N}$ em relação ao tratamento-controle, com exceção da aplicação da menor dose de $\mathrm{N}$ na emissão da 9a folha do CP e no emborrachamento e da aplicação de maior dose de $\mathrm{N}$ no emborrachamento (Figura 1 e Tabela 1). Dentro desse período, considerando somente a aplicação única de cada dose de $\mathrm{N}$, não se observaram diferenças nas taxas de acúmulo de MS entre os estádios fenológicos, com exceção da aplicação da maior dose de $\mathrm{N}$ na emissão da $3^{\text {a }}$ folha, que foi superior à aplicação na emissão da 9a folha. Dessa forma, o período em que as plantas respondem em acúmulo de MS em reposta à aplicação de $\mathrm{N}$ ocorre entre a emergência das plântulas e a emissão da 9a folha do CP. A partir do emborrachamento, não há mais respostas em termos de acúmulo de MS em função da aplicação de $\mathrm{N}$ nesse estádio, provavelmente, porque, a partir desse estádio, esse processo começa a estagnar nas plantas (LAL et al., 1978).

As taxas elevadas de acúmulo de MS com a aplicação de $\mathrm{N}$ da emergência das plântulas até a emissão da $5^{\text {a }}$ folha do CP ocorreram, provavelmente, devido à maior presença de colmos no estádio de alongamento dos colmos (Tabela 2). O maior número de colmos se deve à maior emissão de afilhos, favorecida pela aplicação de $\mathrm{N}$ em estádios iniciais de desenvolvimento dos cereais de estação fria (GROHS et al., 2001). Segundo ALVES et al. (2005), o controle do desenvolvimento dos afilhos não ocorre na diferenciação ou iniciação dos mesmos, mas durante e após a sua emergência. Através de estudos de fotobiologia, observa-se que a definição da emissão do A1, A2 e A3 ocorre entre a emergência das plântulas e a emissão da 4 ${ }^{\mathrm{a}}$ folha do CP (ALMEIDA \& MUNDSTOCK, 2001). Segundo PETR et al. (1988), os fatores que mais contribuem para o abortamento de afilhos iniciados são a disponibilidade hídrica, seguida pela disponibilidade de N. Assim, a maior fixação e desenvolvimento dos afilhos iniciados pela aplicação de $\mathrm{N}$ nesse período pode aumentar a emissão e participação destes no acúmulo de MS durante o alongamento dos colmos. Já as taxas elevadas de acúmulo de MS com a aplicação de $\mathrm{N}$ no período de alongamento dos colmos estão relacionadas, provavelmente, ao maior aporte de $\mathrm{N}$ para este processo, já que a aplicação tardia de $\mathrm{N}$, a partir da emissão da $7^{a}$ folha do $C P$, não incrementa a emissão de afilhos (SIMONS, 1982).

Na análise comparativa entre os coeficientes de regressão linear $(b)$ de duas retas, as taxas de acúmulo de $\mathrm{N}$ da parte área para todos os tratamentos com aplicação diferiram das do tratamento-controle, sem aplicação de N (Figura 2 e Tabela 3). Ao contrário das taxas de acúmulo de MS, houve diferenças entre taxas de acúmulo de $\mathrm{N}$ da parte aérea para todos os tratamentos com aplicação única de N. Neste caso, os maiores acréscimos na taxa de acúmulo de $\mathrm{N}$ da parte aérea foram observados com as aplicações mais tardias, por ocasião da emissão da $7^{\text {a }}$ folha do CP ou do início do alongamento dos colmos. Este resultado confirma o pressuposto da maior necessidade de $\mathrm{N}$ no período de alongamento dos colmos para dar aporte a este processo (MUNDSTOCK, 1999).

Apesar da aplicação de $\mathrm{N}$ nos estádios iniciais de desenvolvimento da cultura terem resultado em maior número de colmos no período de alongamento dos colmos, houve poucas diferenças entre tratamentos para o componente número de espigas área ${ }^{-1}$ (Tabela 2). Todos os tratamentos com aplicação de $\mathrm{N}$ foram superiores ao tratamento controle. Entre os tratamentos com aplicação de N, a aplicação da maior dose de N na emissão da $5^{\text {a }}$ folha do CP produziu o maior número de espigas área ${ }^{-1}$, não diferindo dos demais tratamentos, com exceção ao da aplicação da maior dose de $\mathrm{N}$ na emissão da 9a folha do CP. Esta falta de diferença se deve à maior taxa de sobrevivência de colmos com as aplicações mais tardias de $\mathrm{N}$ (Tabela 2). A média de sobrevivência de colmos, para os tratamentos testados, 


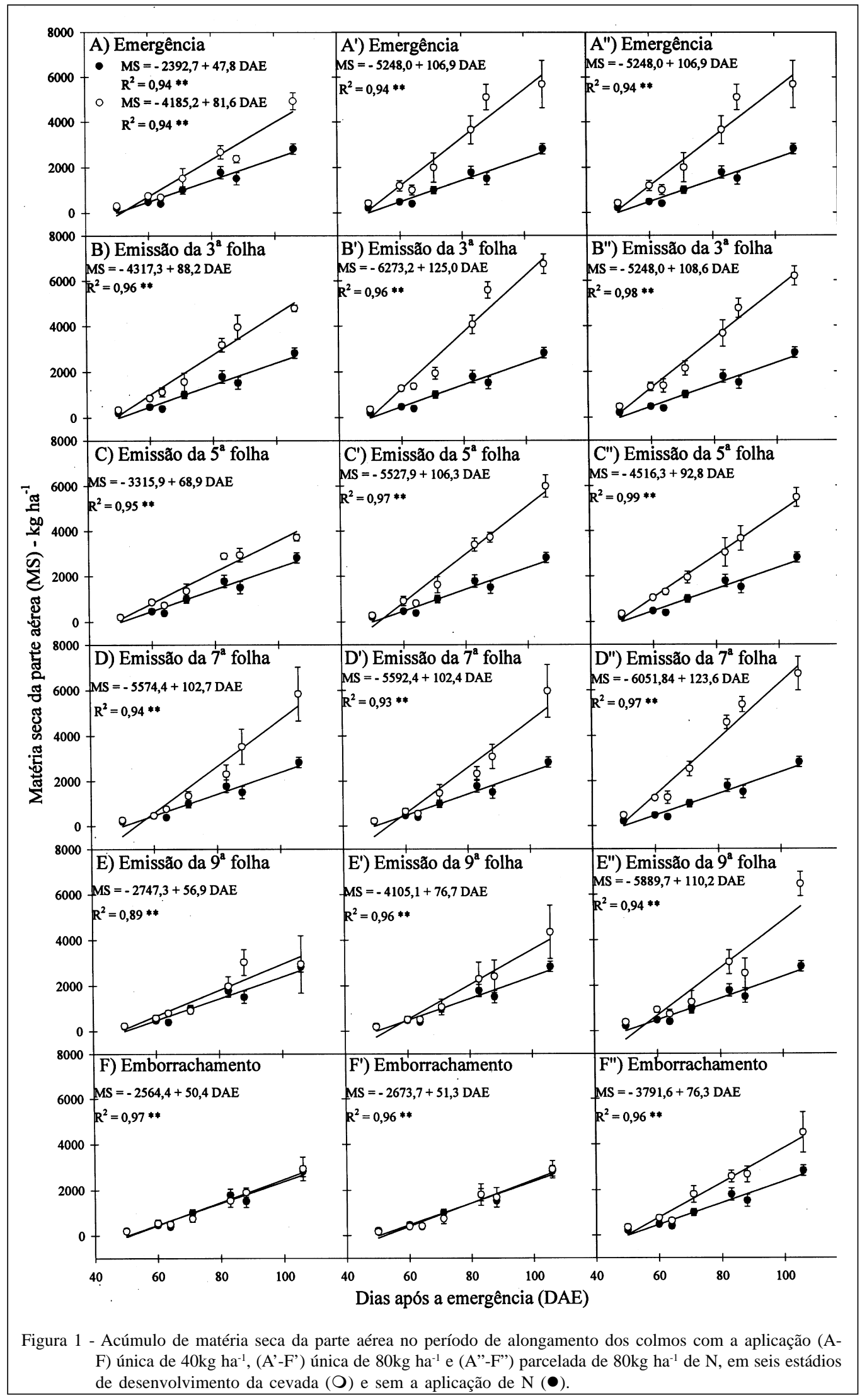

Ciência Rural, v.37, n.6, nov-dez, 2007. 
Tabela 1 - Comparação do coeficiente de regressão linear (b) das equações lineares ajustadas para a evolução de matéria seca da parte aérea em resposta à aplicação de duas doses de $\mathrm{N}$ em seis estádios de desenvolvimento da cevada.

\begin{tabular}{|c|c|c|c|c|c|c|c|c|c|c|c|c|c|c|c|c|c|c|c|}
\hline \multirow{2}{*}{\multicolumn{2}{|c|}{ Tratamentos }} & \multirow{2}{*}{$\begin{array}{c}\text { Sem } \\
\mathrm{N}\end{array}$} & \multicolumn{6}{|c|}{ 40kg ha-1 (aplicação única) } & \multicolumn{6}{|c|}{ 80kg ha ${ }^{-1}$ (aplicação única) } & \multicolumn{5}{|c|}{$\begin{array}{c}\text { 80 } \mathrm{kg} \mathrm{ha}^{-1} \text { (aplicação } \\
\text { parcelada) }\end{array}$} \\
\hline & & & 0.1 & 2.1 & 4.1 & 6.1 & 8.1 & Emb & 0.1 & 2.1 & 4.1 & 6.1 & 8.1 & Emb & 2.1 & 4.1 & 6.1 & 8.1 & Emb \\
\hline \multicolumn{2}{|c|}{ Sem $N$} & - & $* *$ & $* *$ & $* *$ & $* *$ & ns & ns & $* *$ & $* *$ & $* *$ & $* *$ & $* *$ & ns & $* *$ & $* *$ & $* *$ & $* *$ & $* *$ \\
\hline \multirow{5}{*}{ 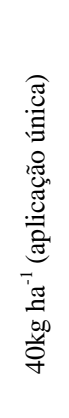 } & 0.1 & & - & ns & ns & ns & $* *$ & $* *$ & ns & ns & ns & ns & ns & $* *$ & ns & ns & ns & ns & ns \\
\hline & 2.1 & & & - & ns & ns & $* *$ & $* *$ & ns & ns & ns & ns & ns & $* *$ & ns & ns & ns & ns & ns \\
\hline & 4.1 & & & & - & ns & ns & $* *$ & $* *$ & $* *$ & $* *$ & ns & ns & $* *$ & $* *$ & ns & $* *$ & $* *$ & ns \\
\hline & 6.1 & & & & & - & $* *$ & $* *$ & ns & ns & ns & ns & ns & $* *$ & $\mathrm{~ns}$ & ns & ns & ns & ns \\
\hline & 8.1 & & & & & & - & ns & $* *$ & $* *$ & $* *$ & $* *$ & ns & ns & $* *$ & $* *$ & $* *$ & $* *$ & ns \\
\hline & Emb & & & & & & & - & $* *$ & $* *$ & $* *$ & $* *$ & $* *$ & ns & $* *$ & $* *$ & $* *$ & $* *$ & $* *$ \\
\hline \multirow{6}{*}{ 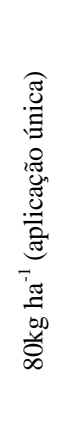 } & 0.1 & & & & & & & & - & ns & ns & ns & ns & $* *$ & ns & ns & ns & ns & ns \\
\hline & 2.1 & & & & & & & & & - & ns & ns & $* *$ & $* *$ & ns & ns & ns & ns & $* *$ \\
\hline & 4.1 & & & & & & & & & & - & ns & ns & $* *$ & ns & ns & ns & ns & ns \\
\hline & 6.1 & & & & & & & & & & & - & ns & $* *$ & ns & ns & ns & ns & ns \\
\hline & 8.1 & & & & & & & & & & & & - & $* *$ & $\mathrm{~ns}$ & ns & $* *$ & ns & ns \\
\hline & Emb & & & & & & & & & & & & & - & $* *$ & $* *$ & $* *$ & $* *$ & $* *$ \\
\hline \multirow{5}{*}{ 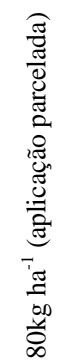 } & 2.1 & & & & & & & & & & & & & & - & ns & ns & ns & ns \\
\hline & 4.1 & & & & & & & & & & & & & & & - & ns & ns & ns \\
\hline & 6.1 & & & & & & & & & & & & & & & & - & ns & $* *$ \\
\hline & 8.1 & & & & & & & & & & & & & & & & & - & ns \\
\hline & Emb & & & & & & & & & & & & & & & & & & - \\
\hline
\end{tabular}

**coeficientes de regressão linear (b) de duas retas se diferem pelo teste de t, a $1 \%$ de probabilidade; ns = não há diferenças entre os coeficientes de regressão linear (b) das duas retas pelo teste de t, a $1 \%$ de probabilidade.

situou-se em 51\%. Os tratamentos que receberam $\mathrm{N}$ nos estádios iniciais de desenvolvimento, da emergência até a emissão da $5 \underline{a}$ folha, foram os que resultaram na menor sobrevivência de colmos observada para os três manejos do N. O maior número de colmos formados com as aplicações de $\mathrm{N}$ nos estádios iniciais formam um maior potencial de demanda por nutrientes no período de alongamento dos colmos.
Porém, esta disponibilidade inicial de $\mathrm{N}$ não foi suficiente para atender às demandas pelo nutriente no período de alongamento dos colmos, intensificando a competição entre colmos, na qual os mais tardios e menos competitivos levam desvantagem na competição e senescem (DAVIDSON \& CHEVALIER, 1990). Segundo MUNDSTOCK \& BREDEMEIER (2001), a menor disponibilidade de $\mathrm{N}$ no período de alongamento 
Tabela 2 - Número de colmos no alongamento dos colmos, número de espigas na maturação de colheita e porcentagem de sobrevivência de colmos em função da aplicação de $\mathrm{N}$ em seis estádios de desenvolvimento da cevada.

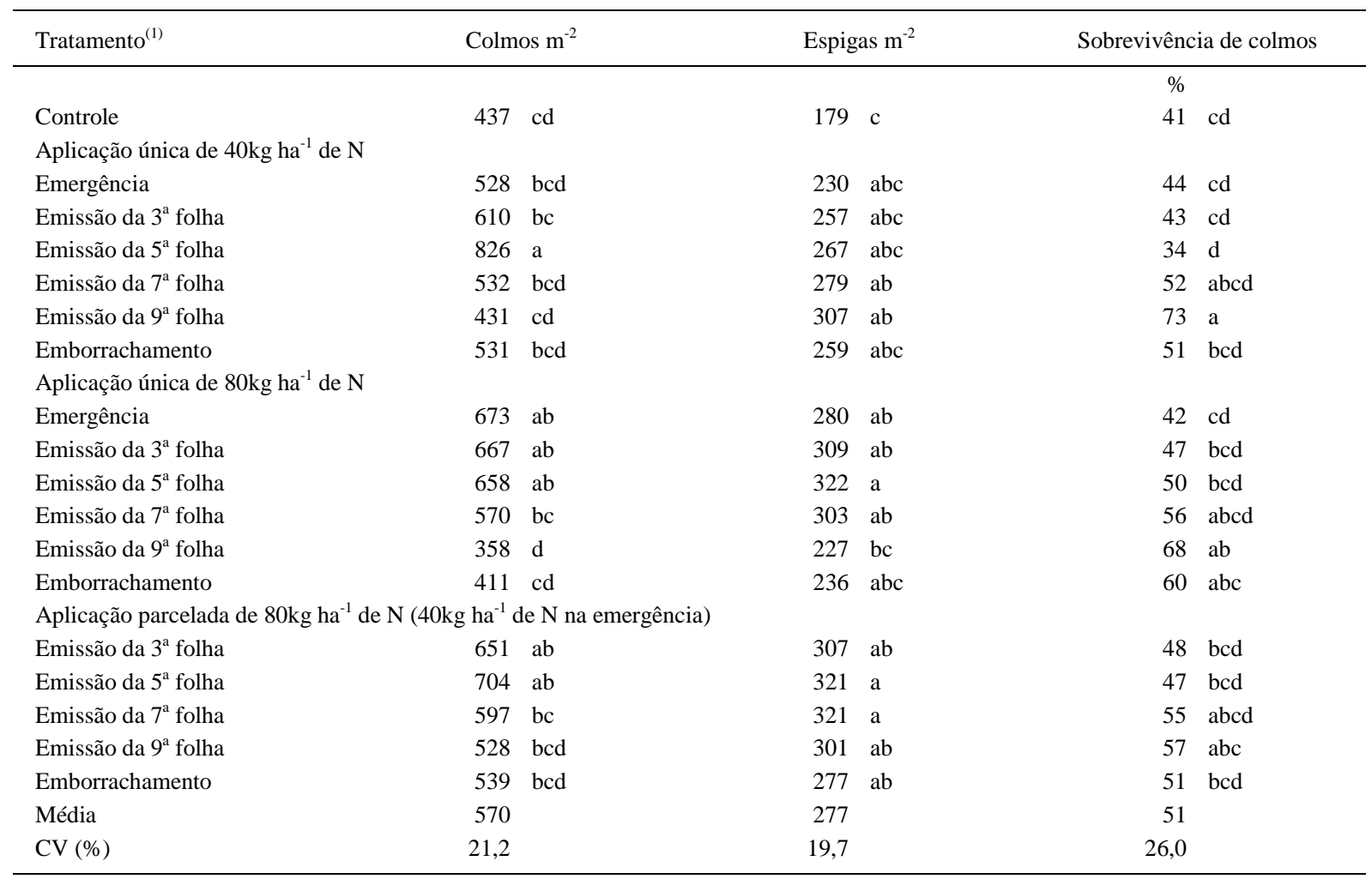

${ }^{(1)}$ Médias seguidas pela mesma letra na coluna não diferem entre si pelo teste de Duncan, a 5\% de significância.

dos colmos também acarreta a falta de sincronismo na emissão de folhas entre o CP e os afilhos. Esta falta de sincronismo de desenvolvimento também determina a mortalidade de afilhos (DAVIDSON \& CHEVALIER, 1990).

As aplicações mais tardias de $\mathrm{N}$, a partir da emissão da $7^{a}$ folha do $\mathrm{CP}$, favoreceram a maior sobrevivência de colmos, sendo que a aplicação de N por ocasião da emissão da 9 a folha apresentou a maior percentagem de colmos que produziram uma inflorescência fértil, para os três manejos do N. Neste trabalho, as aplicações de $\mathrm{N}$ na emissão da $7 \stackrel{\text { a }}{\text { folha do }}$ $\mathrm{CP}$ proporcionaram maiores rendimentos de grãos em relação aos demais manejos de $\mathrm{N}$, enquanto que a proteína bruta no grão não ultrapassou o teor de $11 \%$ com as aplicações de $\mathrm{N}$ até este estádio (dados não publicados). A maior sobrevivência de colmos com a

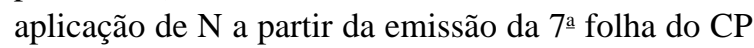
referenda a importância do aporte de $\mathrm{N}$ ao processo de acúmulo de MS durante o período de alongamento dos colmos com o objetivo de diminuir a competição entre os colmos por este nutriente (EASSON, 1984) e aumentar o sincronismo de desenvolvimento do afilho com o CP(MUNDSTOCK \& BREDEMEIER, 2001). Este período se estende deste o início até a metade do período de alongamento dos colmos. Nem sempre este comportamento é observado (RAMOS et al., 1995), mas ele mostra que na emissão da 9a folha do CP ainda não está fixado o número de afilhos que possuem potencial para produzirem espigas, ao contrário do exposto por GARCIA DEL MORAL et al. (1984).

\section{CONCLUSÃO}

A aplicação de $\mathrm{N}$ entre a emergência das plântulas e a emissão da 9a folha do CP favorece o acúmulo de MS da parte aérea. Entretanto, maiores taxas de acúmulo de $\mathrm{N}$ são observadas com a aplicação de $\mathrm{N}$ a partir do início do alongamento dos colmos, devido à exigência das plantas pelo $\mathrm{N}$ para dar aporte ao processo de alongamento dos colmos. A aplicação de $\mathrm{N}$ no período de alongamento dos colmos diminui a competição entre os colmos pelo nutriente, favorecendo maiores taxas de sobrevivência de colmos. 


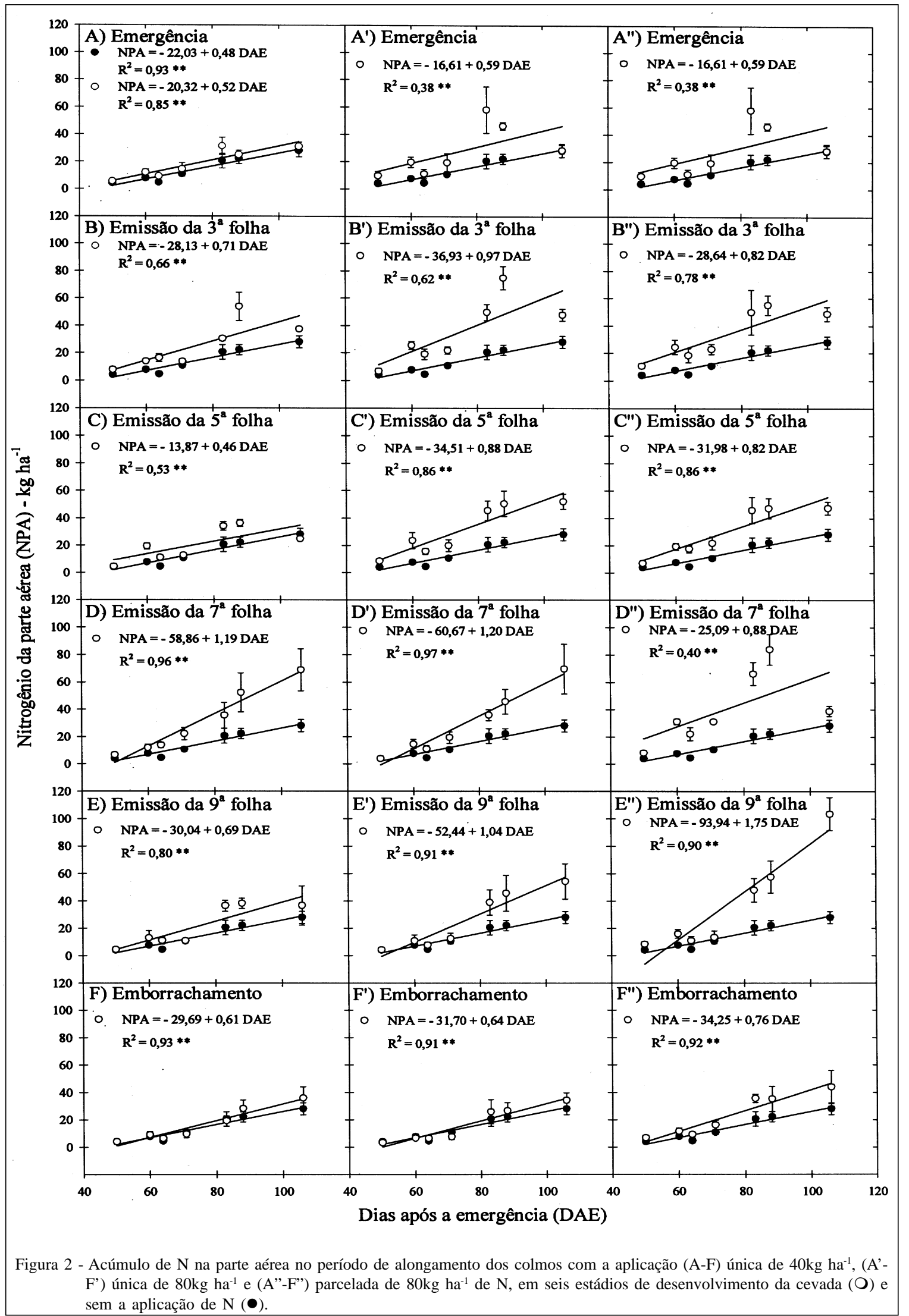

Ciência Rural, v.37, n.6, nov-dez, 2007. 
Tabela 3 - Comparação do coeficiente de regressão linear (b) das equações lineares ajustadas para a evolução de N da parte aérea, em resposta à aplicação de duas doses de $\mathrm{N}$ em seis estádios de desenvolvimento da cevada.

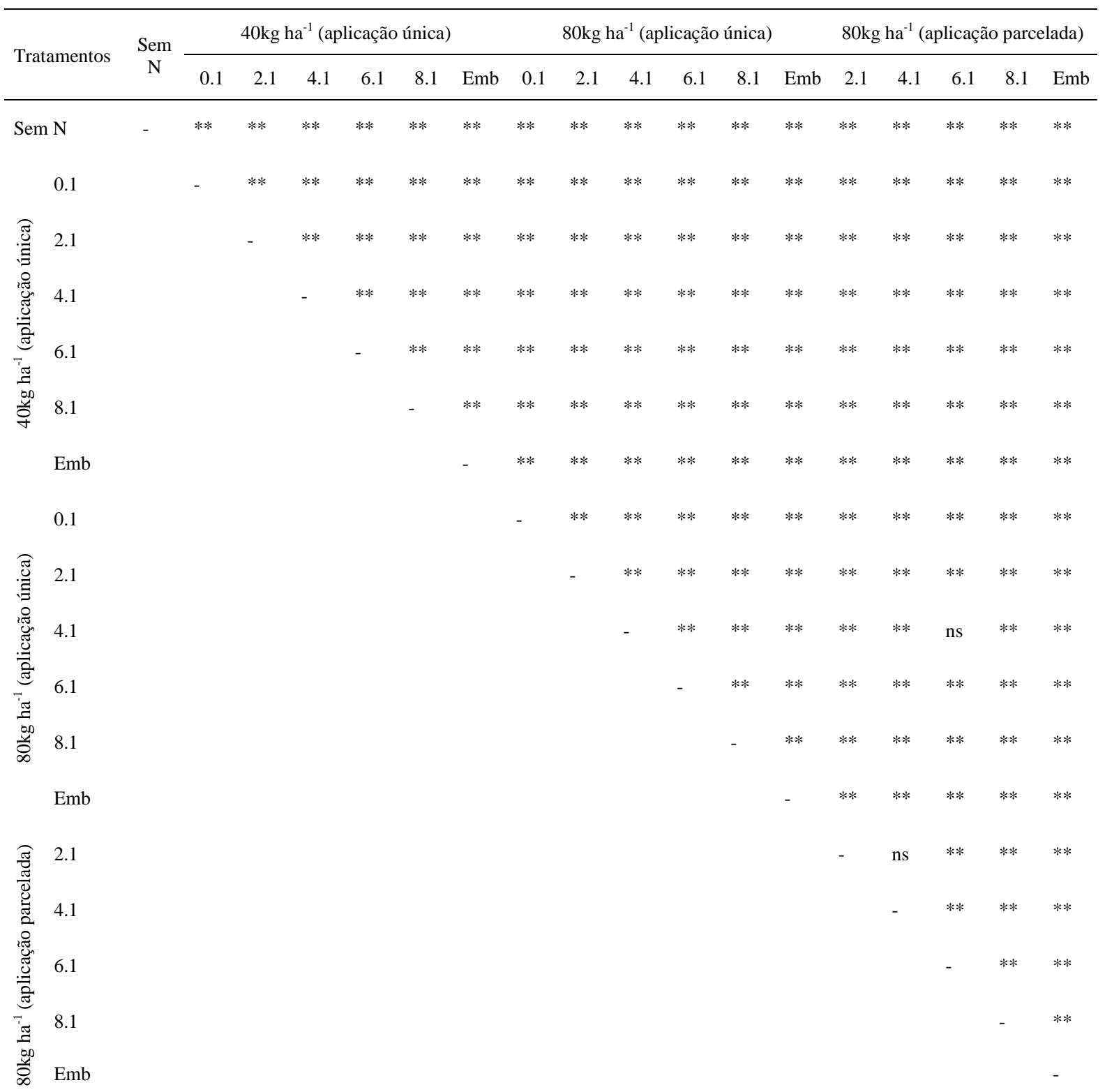

** coeficientes de regressão linear (b) de duas retas se diferem pelo teste de t, a 1\% de probabilidade; ns = não há diferenças entre os coeficientes de regressão linear (b) das duas retas pelo teste de t, a 1\% de probabilidade.

\section{REFERÊNCIAS}

ALMEIDA, M.L.; MUNDSTOCK, C.M. A qualidade da luz afeta o afilhamento em plantas de trigo quando cultivada sob competição. Ciência Rural, Santa Maria, v.31, n.3, p.401408, 2001.

ALVES, A.C. et al. Iniciação e emergência de afilhos em cereais de estação fria. Ciência Rural, Santa Maria, v.35, n.1, p.3945, 2005.
BREMNER, P.M. Growth and yield of three varieties of wheat, with particular reference to the influence of unproductive tillers. Journal of Agricultural Science, Cambridge, v.72, n.2, p.281-287, 1969.

CHATURVEDI, G.S. et al. Effect of irrigation on tillering in wheat, triticale and barley in a water limited environment. Irrigation Science, Heidelberg, v.2, n.4, p225-235, 1981.

COMISSÃO DE PESQUISA DE CEVADA. Recomendações técnicas da Comissão de Pesquisa de Cevada para o

Ciência Rural, v.37, n.6, nov-dez, 2007. 
cultivo de cevada cervejeira em 1999 e 2000. Passo Fundo: Embrapa Trigo, 1999. V.1, 71p.

DARROCH, B.A.; FOWLER, D.B. Dry matter production and nitrogen accumulation in no-till winter wheat. Canadian Journal of Plant Science, Ottawa, v.70, n.2, p.461-472, 1990.

DAVIDSON, D.J.; CHEVALIER, P.M. Preanthesis tiller mortality in spring wheat. Crop Science, Madison, v.30, n.4 p.832-836, 1990.

EASSON, D.L. The timing of nitrogen application for spring barley. Journal of Agricultural Science, Cambridge, v.102, n.3, p.673-678, 1984.

GARCÍA DEL MORAL, L.F. et al. Tillering dynamics of winter barley as influenced by cultivar and nitrogen fertilizer: a field study. Crop Science, Madison, v.24, n.1, p.179-181, 1984

GROHS, D.S. et al. O padrão de afilhamento em cevada afetado pela disponibilidade de N. In: REUNIÃO ANUAL DE PESQUISA DE CEVADA, 21., 2001, Guarapuava, PR. Anais e Ata... Passo Fundo: Embrapa Trigo, 2001. p.191-198.

HAUN, J.R. Visual quantification of wheat development. Agronomy Journal, Madison, v.65, n.1, p.116-119, 1973.

LAL, P. et al. Accumulation and redistribution pattern of dry matter and $\mathrm{N}$ in triticale and wheat varieties under water stress conditions. Agronomy Journal, Madison, v.70, n.4, p.623626, 1978.

MASLE-MEYNARD, J. Elaboration du nombre d'épis d'un peuplement de blé d'hiver en situation de compétition pour l'azote. I. Mise en évidence d'un stade critique pour la montée d'une talle. Agronomie, Versailles, v.1, p.623-632, 1981.

MUNDSTOCK, C.M. Planejamento e manejo integrado da lavoura de trigo. Porto Alegre: Ed. do autor, 1999. 228p.

MUNDSTOCK, C.M.; BREDEMEIER, C. Disponibilidade de nitrogênio e sua relação com o afilhamento e o rendimento de grãos de aveia. Ciência Rural, Santa Maria, v.31, n.2, p.205211, 2001

PETR, J. et al. Yield formation in cereals. In: PETR, J. et al. Yield formation in the main field crops. Amsterdam: Elsevier, 1988. p.72-153.

RAMOS, J.M. et al. Barley response to rate and timing in a Mediterranean environment. Journal of Agricultural Science, Cambridge, v.125, n.2, p.175-182, 1995

RAO, S.C.; DAO, T.H. Nitrogen placement and tillage effects on dry matter and nitrogen accumulation and redistribution in winter wheat. Agronomy Journal, Madison, v.88, n.3, p.365371, 1996.

SIMMONS, S.R. et al. Tillering in barley: genotype, row spacing, and seedling rate effects. Crop Science, Madison, v.22, n.4, p.801-805, 1982.

SIMONS, R.G. Tiller and ear production of winter wheat. Field Crop Abstract, Oxon, v.35, n.11, p.857-870, 1982

TEDESCO, M.J. et al. Análises de solo, plantas e outros materiais. 2.ed. Porto Alegre: Departamento de Solos da UFRGS, 1995. 174p. (Boletim Técnico de Solos, 5). 